\title{
Outcomes and Risk Factors Affecting Mortality in Patients Who Underwent Colorectal Emergency Surgery
}

\author{
Nam Ho Oh, Kyung Jong Kim \\ Department of Surgery, Chosun University Medical School, Gwangju, Korea
}

Purpose: Emergency colorectal surgery has a high risk of mortality and morbidity because of incomplete bowel preparation, bacterial proliferation, and contamination. In this study, we investigated the outcomes and the risk factors affecting mortality in patients who had undergone emergency surgery for the treatment of various colorectal diseases.

Methods: This study is a retrospective analysis of prospectively collected data to survey the clinical results for patients who had undergone emergency colorectal surgery from January 2014 to December 2014. We analyzed various clinicopathologic factors, which were divided into 3 categories: preoperative, intraoperative, and postoperative.

Results: A total of 50 patients had undergone emergency colorectal surgery during the time period covered by this study. Among them, 10 patients (20\%) died during the postoperative period. A simple linear regression analysis showed that the risk factors for mortality were old age, preoperative hypotension, and a high American Society of Anesthesiologist (ASA) score. Moreover, a multiple linear regression analysis showed a high ASA score and preoperative hypotension to be independent risk factors.

Conclusion: In this study, emergency colorectal surgery showed a relatively high mortality rate. Furthermore, the independent risk factors for mortality were preoperative hypotension and high ASA score; thus, patients with these characteristics need to be evaluated more carefully and receive better care if the mortality rate is to be reduced.

\section{Keywords: Emergencies; Hypotension; Colorectal surgery; Mortality; Risk factors}

\section{INTRODUCTION}

Recently, due to the aging of society and the Westernization of dietary behaviors, the number of cases involving not only colorectal cancer but also benign colorectal diseases, such as diverticulitis and ischemic bowel disease, have been increasing. For colorectal disease, early diagnosis and treatment is now possible owing to the development of diagnostic methods such as colonoscopy and computed tomography of the abdomen. Nevertheless, for colorectal cancer, the proportions of patients with associated intestinal

Received: April 25, 2016 - Accepted: August 4, 2016

Correspondence to: Kyung Jong Kim, M.D.

Department of Surgery, Division of Colon and Rectum, Chosun University

Medical School, 309 Pilmun-daero, Dong-gu, Gwangju 61452, Korea

Tel: +82-62-220-3983, Fax: +82-62-228-3441

E-mail: kjkim@mail.chosun.ac.kr

(c) 2016 The Korean Society of Coloproctology

This is an open-access article distributed under the terms of the Creative Commons Attribution NonCommercial License (http://creativecommons.org/licenses/by-nc/4.0) which permits unrestricted noncommercial use, distribution, and reproduction in any medium, provided the original work is properly cited. obstruction or perforation not receiving timely treatment have been reported to be $8 \%-29 \%$ and $3 \%-8 \%$, respectively. Because of the recent development of antibiotics, conservative treatment is used for benign diseases, including diverticulitis and ischemic bowel disease; however, surgery is still considered to be an important treatment modality for patients with severe peritoneal contamination or severe sepsis [1-5].

In the studies so far, colorectal surgery has shown a relatively high level of mortality and many complications. Especially, in those who underwent emergency surgeries for colorectal diseases, because of insufficient time being available, preoperational bowel preparation was more difficult than it was in patients scheduled for surgery, and such emergency surgeries are primarily encountered in elderly patients, resulting in high rates of mortality and complications. Several past studies have shown the mortality and complication rates in patients who received emergency colorectal resections to be $10 \%-25 \%$ and $30 \%-50 \%$, respectively [6-8]. Such high risks are affected by several factors, such as the condition of the patient, existing comorbidities, and the type of disease. However, studies related to patients in the Eastern world, including the 
Republic of Korea, who underwent emergency colorectal surgery, are not sufficient [9-12].

Emergency colorectal surgery may be performed for reasons such as perforation, obstruction and bleeding, and the outcome may depend on many factors such as underlying diseases and surgical method used; thus, cases may vary greatly, depending on the details. Because of this, studies on the postoperative outcomes and the risk factors of emergency colorectal surgery are important, and in fact, more data based on more studies are required. To this end, in this study, the authors aimed to identify risk factors for patients who underwent the emergency surgery to treat colorectal diseases and hoped that the results would be helpful for lowering the perioperative mortality and complication rates through alleviation of identified risk factors.

\section{METHODS}

This study is an Interim Clinical Study Report of a prospective study conducted from January 2014 to December 2015, "Assessment of Clinical Outcomes and Risk Factors in Patients Who Underwent Colorectal Emergency Surgery." The study analyzed retrospectively the clinical outcomes in patients who underwent emergency colorectal surgery from among those who visited the Emergency Department with colorectal disease and were found to be in need of surgery within 24 hours and in patients who were medically treated by another department or our department at our hospital from January 2014 to December 2015. Emergency surgery, including a laparotomy and laparoscopy, was performed on the patients with colorectal diseases under general anesthesia.

The preoperative assessment included gender, age, presence or absence of comorbidities, and hypotension defined as a systolic blood pressure of $90 \mathrm{mmHg}$. In addition, a survey was conducted by using the American Society of Anesthesiologist classification score (ASA score), that score being based on the physical condition of patients undergoing the surgery and anesthesia. Intraoperative observations, such as the indications for surgery, the operating time, the operating surgeon and the amount of blood transfused, were recorded and evaluated. After the surgery, complications and death that occurred during both biopsy and hospital stay, as well as the length of hospital stay, were observed and recorded. Operative death was defined as death occurring while in the hospital following surgery. The etiology was recorded as colorectal cancer, diverticulitis, obstruction due to feces, and unknown causes. As for complications, major pathologic symptoms that might threaten the life of patients, such as bowel obstruction, pneumonia, sepsis, renal failure, hemorrhage and pulmonary embolism, were recorded.

For statistical analysis, PASW Statistics ver. 18.0 (SPSS Inc., Chicago, IL, USA) was used, and a univariate analysis was conducted on the patient-related factors and the surgery-related factors, and the relationship between the mortality and the complication rates were evaluated by using the chi-squared test. Factors with P-val- ues $\leq 0.05$ were selected, and significant factors were identified after a multivariate analysis had been performed using a logistic regression. Those factors with P-values $\leq 0.05$ were considered to be statistically significant.

\section{RESULTS}

During the study period, emergency colorectal surgery was performed on 50 patients, 26 males and 24 females, with a mean age of $70.25 \pm 12.50$ years. The most often encountered underlying diseases of the patients were hypertension and diabetes. The patients were classified according to the ASA classification, and 15 were found to be grade 1, 21 grade 2, 8 grade 3 , and 6 to be grade 4. The physical examinations conducted on admission showed that 17 patients (34\%) had hypotension (systolic blood pressure of $90 \mathrm{mmHg}$ ). Twenty-three patients received blood transfusions during surgery, and the most frequent surgical site was the sigmoid colon, followed in sequence by the ascending colon, the descending colon, and the transverse colon. The average operative time was $170.98 \pm 61.05$ minutes (Table 1). The most common indications for surgery were perforations in 38 patients; other indications included obstruction, ischemia and megacolon. The etiologies were colorectal cancer in 9 patients (18\%), diverticulitis in 12 patients (24\%), ischemic colitis in 16 patients (32\%), fecal impaction in 5 patients $(10 \%)$ and unknown in 8 patients (16\%).

Twenty-nine surgeries (58\%) were performed by specialists, 4 (8\%) by residents, and 17 (34\%) by general surgeons. As for the type of surgery, Hartmann surgery was conducted in 26 patients (52\%), followed by an intestinal resection in 13 patients (26\%), ostomy surgery in 8 patients (16\%), and primary repair in 3 patients (6\%). Ten postoperative deaths (20\%) occurred, and 8 of those involved patients were a perforation. The causal diseases of the deceased patients were ischemic colitis in 5 patients, fecal obstruction in 3 patients, and diverticulitis and unknown cause in 1 patient each. Nine of the 17 patients with preoperative hypotension died, and of those nine, 5 were grade 3 or grade 4 according to the ASA score. The major postoperative complications recorded were pneumonia, intestinal obstruction, renal failure, sepsis, and pulmonary embolism. Some complications were found in multiple patients, so the entire number of patients with complications was $15(30 \%)$. However, minor complications such as surgical wound infections, pleural effusion, and atelectasis were not included as complications. The average hospital stay for all patients was $16.22 \pm 11.48$ days (Table 2).

A univariate analysis was performed using the specified factors to identify their respective relationships with mortality during hospital stay. The results showed that patients older than 70 years of age displayed higher mortality $(\mathrm{P}=0.031)$. Also, patients in a state of shock associated with hypotension, as identified during the preoperative examinations, showed a higher rate of mortality $(\mathrm{P}=0.000)$. Moreover, the higher the ASA score was, the higher the mortality that was observed $(\mathrm{P}=0.000)$. However, no statisti- 
Table 1. Patients' demographics, preoperation state, comorbid disease, location of disease, and perioperative transfusion

\begin{tabular}{lc}
\hline Characteristic & Value \\
\hline Male sex & $26(52)$ \\
Age (yr) & $70.25 \pm 12.50$ \\
Comorbid disease & $26(52)$ \\
Hypertension & $13(26)$ \\
DM & $4(8)$ \\
ESRD & $4(8)$ \\
CVA & $1(2)$ \\
COPD & \\
Location & $9(18)$ \\
Ascending colon & $1(2)$ \\
Transverse colon & $3(6)$ \\
Descending colon & $25(50)$ \\
Sigmoid colon & $12(24)$ \\
Rectum & \\
ASA score & $15(30)$ \\
1 & $21(42)$ \\
2 & $8(16)$ \\
3 & $7(14)$ \\
4 & $17(34)$ \\
Preoperative hypotension & $23(46)$ \\
Perioperative transfusion & $170.98 \pm 61.05$ \\
Operation time (min) & \\
\hline
\end{tabular}

Values are presented as number (\%) or mean \pm standard deviation.

DM, diabetes mellitus; ESRD, end-stage renal disease; CVA, cerebrovascular accident; COPD, chronic obstructive pulmonary disease; ASA, American Society of Anesthesiologist.

cally significant relations of such factors as the receipt of a blood transfusion, the surgeon, the type of surgery, and the perioperative etiology to mortality were noted. In addition, when the patients were divided according to the duration of surgery into 2 groups, the long-duration and the short-duration groups, and the outcomes were compared, no statistically significant differences were found. When a multivariate analysis involving the variables found to have significant differences from the univariate analysis was conducted, the ASA score and preoperative hypotension were found to be independently significant, with P-values of 0.000 and 0.003 , respectively. Although age older than 70 years was found on the univariate analysis to be a significant factor related to mortality, the P-value for age older than 70 years on the multivariate analysis was 0.553 ; thus, age older than 70 years was not a statistically-significant independent factor related to mortality (Table 3).

\section{DISCUSSION}

Previous results for patients who underwent emergency colorec-
Table 2. Character of surgery, cause of disease, and postoperative outcomes

\begin{tabular}{|c|c|}
\hline Variable & Value \\
\hline \multicolumn{2}{|l|}{ Indication of surgery } \\
\hline Perforation & $38(76)$ \\
\hline Obstruction & $5(10)$ \\
\hline Ischemia & $6(12)$ \\
\hline Megacolon & $1(2)$ \\
\hline \multicolumn{2}{|l|}{ Cause of disease } \\
\hline Malignancy & $9(18)$ \\
\hline Diverticulitis & $12(24)$ \\
\hline Ischemia colitis & $16(32)$ \\
\hline Stercoral & $5(10)$ \\
\hline Unknown & $8(16)$ \\
\hline \multicolumn{2}{|l|}{ Qualification of surgeon } \\
\hline Trainee & $4(8)$ \\
\hline General surgeon & $17(34)$ \\
\hline Colorectal surgeon & $29(58)$ \\
\hline \multicolumn{2}{|l|}{ Type of surgery } \\
\hline Hartmann operation & $26(50)$ \\
\hline Resection and anastomosis & $13(26)$ \\
\hline Stoma & $8(16)$ \\
\hline Primary repair & $3(6)$ \\
\hline \multicolumn{2}{|l|}{ Postoperative outcome } \\
\hline Mortality & $10(20)$ \\
\hline Overall morbidity & $15(30)$ \\
\hline Hospital days & $16.22 \pm 11.48$ \\
\hline \multicolumn{2}{|l|}{ Morbidity } \\
\hline Sepsis & $8(16)$ \\
\hline Acute renal failure & $7(14)$ \\
\hline lleus & $6(12)$ \\
\hline Wound dehiscence & $6(12)$ \\
\hline
\end{tabular}

Values are presented as number (\%) or mean \pm standard deviation.

tal surgery for various reasons showed mortality and complication rates of $10 \%-25 \%$ and $30 \%-50 \%$, respectively [6-8]. However, these results are mostly from the Western world, with clinical results for emergency colorectal surgery in Korea or in the Eastern world being scarce [9-12]. In particular, because only a few reports have been published on the results of emergency colorectal surgery performed for various reasons, the results of this study are believed to be significant.

Factors related to the patient, such as old age and the presence of comorbidities, including diabetes and chronic kidney disease, are widely known to be associated with the prognosis after surgery. The univariate analysis in this study identified age older than 70 
Table 3. Factors related to mortality based on univariate and multivariate analyses

\begin{tabular}{|c|c|c|c|c|}
\hline \multirow[b]{2}{*}{ Variable } & \multicolumn{2}{|c|}{ Univariate analysis } & \multicolumn{2}{|c|}{ Multivariate analysis } \\
\hline & $\begin{array}{c}\text { Mortality, } \\
\mathrm{n}(\%)\end{array}$ & P-value & $\begin{array}{c}\text { Adjusted } \\
\text { OR }(95 \% \text { Cl) }\end{array}$ & P-value \\
\hline \multicolumn{5}{|l|}{ Age (yr) } \\
\hline$\geq 70$ & 9/20 (45) & 0.031 & 1 & 0.553 \\
\hline$<70$ & 1/31 (3.2) & & $1.15(0.65-2.08)$ & \\
\hline Patient with comorbidity & 9/39 (23) & 0.316 & & \\
\hline Preoperative hypotension & 9/17 (52.9) & 0.000 & $1.59(1.04-2.48)$ & 0.003 \\
\hline ASA score & & 0.000 & & 0.000 \\
\hline 1 & 0/15 (0) & & 1 & \\
\hline 2 & $0 / 21(0)$ & & $1.58(1.15-2.08)$ & \\
\hline 3 & $5 / 8(62.5)$ & & & \\
\hline 4 & $5 / 6(83.3)$ & & & \\
\hline Perioperative transfusion & 6/23 (26) & 0.331 & & \\
\hline Qualification of surgeon & & 0.590 & & \\
\hline Trainee & $2 / 4(50.0)$ & & & \\
\hline General surgeon & 2/17 (11.7) & & & \\
\hline Colorectal surgeon & 6/29 (20.6) & & & \\
\hline \multicolumn{5}{|l|}{ Operation time (min) } \\
\hline$<170$ & $6 / 28(21.4)$ & 0.781 & & \\
\hline$\geq 170$ & 4/22 (18.1) & & & \\
\hline Type of surgery & & 0.882 & & \\
\hline Hartmann operation & 5/26 (19.2) & & & \\
\hline Bowel resection & 2/13 (15.3) & & & \\
\hline Stoma & $3 / 8(37.5)$ & & & \\
\hline Primary repair & $0 / 3(0)$ & & & \\
\hline Indication of surgery & & 0.656 & & \\
\hline Perforation & 8/38 (21.1) & & & \\
\hline Obstruction & $1 / 5(20.0)$ & & & \\
\hline Ischemia & 1/6 (16.6) & & & \\
\hline Megacolon & $0 / 1(0)$ & & & \\
\hline Cause disease & & 0.308 & & \\
\hline Malignancy & 1/9 (11.1) & & & \\
\hline Diverticulitis & 1/12 (8.3) & & & \\
\hline Ischemia colitis & $4 / 16(25.0)$ & & & \\
\hline Stercoral & $3 / 5(60.0)$ & & & \\
\hline Unknown & $1 / 8(12.5)$ & & & \\
\hline
\end{tabular}

ASA, American society of anesthesiologist; OR, odds ratio; $\mathrm{Cl}$, confidence interval.

years to be associated with a high mortality rate after emergency surgery, but the multivariate analysis did not identify old age as an independent factor associated with mortality. In patients who underwent emergency colorectal surgery, the mortality rates differed with the ASA score. The higher the ASA score was, the poorer the prognosis for the patient was. The ASA score was used to assess the physical conditions of the patient as a predictor of patient outcome during and after surgery [13-15]. According to the study of Bernard et al. [16], perioperative blood transfusion was likely to cause an increase in mortality, but in this study, perioperative blood transfusion was not significantly related to mortality. Because the study of Bernard et al. [16] focused on all surgeries, further study seems to be needed in order to determine the outcomes that would have significance in surgery for colorectal diseases. According to the study of Post et al. [17], intraoperative hypotension was found to be highly related to complications, such as a leakage, after colorectal surgery. However, studies on the effect of preoperative hypotension on patients undergoing emergency colorectal surgery are not sufficient. In this study, we found that the prognosis was not good for patient that experienced the symptoms of shock due to preoperative hypotension. Thus, in our opinion, preoperative hypotension should be useful in the postoperative management of patients because it is a factor that is easy to check, but further study is needed.

According to studies addressing the patient's underlying disease and prognosis, the mortality rate for a patient who undergoes emergency colorectal surgery due to perforation is about $15 \%$ $20 \%[18-20]$. The mortality and the complication rates associated with emergency colorectal surgery for acute obstruction are 15\%$20 \%$ and $40 \%-50 \%$, respectively [21,22]. Moreover, the mortality and the complications rates are higher for patients that undergo emergency surgery rather than regularly-scheduled surgery. This is especially true for patients who undergo emergency colorectal surgery for cancer $[23,24]$. The results of this study are similar, with mortality and complication rates of $20 \%$ and $30 \%$, respectively.

In this study, ischemic colitis was the most frequent cause of emergency surgery among the patients who underwent emergency surgery for colorectal disease. According to other reports in the literature, many emergency colorectal surgeries are due to malignant diseases and perforation of diverticulitis [23, 24]. However, for patients who undergo radical surgery, including stent insertion, after conservative treatment for colorectal cancer and for complications such as perforation of diverticulitis and abscess, the frequency of emergency surgery seems to be lower due to such factors as the use of antibiotics and percutaneous drainage [1-4, $25,26]$.

In terms of the type of surgery and the qualifications of the surgeon, no statistically significant differences in either the mortality or the complication rates were observed in this study. However, previous studies reported that intervention by a specialist in colorectal surgery helped to improve the long-term prognosis, although the acute-period mortality was not significant [27, 28]. In addition, in this study, a higher preoperative ASA score and the presence of preoperative hypotension were found to be associated with a poor prognosis. As for the cause of surgery, the number of 
surgeries performed due to perforation was high, as was the mortality rates. As for the etiologies, benign ischemic colitis and diverticulitis were very common, and mortality was found to be high in patients with acute renal failure accompanied by sepsis after surgery.

In conclusion, in this study, a high mortality of $20 \%$ was observed in patients who underwent emergency surgery for colorectal disease. Furthermore, preoperative hypotension and ASA score were identified as independent risk factors associated with mortality. Thus, more attention should be paid to intensive observation and postoperative management of patients with preoperative hypotension and high ASA score. The preoperative conditions of such patients should be carefully assessed, and a plan for surgery and postoperative management should be established based on those conditions. Overall, more efforts should be put into lowering the mortality rate. A major limitation of this study is that it may show statistical bias due to the small number of patients. Regarding this limitation, we intend to conduct a study with a larger sample size, and to that end, we will continue to collect data on current patients.

\section{CONFLICT OF INTEREST}

No potential conflict of interest relevant to this article was reported.

\section{ACKNOWLEDGMENTS}

This study was supported by a grant from Chosun University (2012).

\section{REFERENCES}

1. Tekkis PP, Poloniecki JD, Thompson MR, Stamatakis JD. Operative mortality in colorectal cancer: prospective national study. BMJ 2003;327:1196-201.

2. Tobaruela E, Camuñas J, Enríquez-Navascúes JM, Díez M, Ratia T, Martín A, et al. Medical factors in the morbidity and mortality associated with emergency colorectal cancer surgery. Rev Esp Enferm Dig 1997;89:13-22.

3. Edna TH, Jamal Talabani A, Lydersen S, Endreseth BH. Survival after acute colon diverticulitis treated in hospital. Int J Colorectal Dis 2014;29:1361-7.

4. Martel J, Raskin JB; NDSG. History, incidence, and epidemiology of diverticulosis. J Clin Gastroenterol 2008;42:1125-7.

5. Ryoo SB, Oh HK, Ha HK, Moon SH, Choe EK, Park KJ. The outcomes and prognostic factors of surgical treatment for ischemic colitis: what can we do for a better outcome? Hepatogastroenterology 2014;61:336-42.

6. Isbister WH, Prasad J. Emergency large bowel surgery: a 15-year audit. Int J Colorectal Dis 1997;12:285-90.

7. Han EC, Ryoo SB, Park BK, Park JW, Lee SY, Oh HK, et al. Surgi- cal outcomes and prognostic factors of emergency surgery for colonic perforation: would fecal contamination increase morbidity and mortality? Int J Colorectal Dis 2015;30:1495-504.

8. Aydin HN, Tekkis PP, Remzi FH, Constantinides V, Fazio VW. Evaluation of the risk of a nonrestorative resection for the treatment of diverticular disease: the Cleveland Clinic diverticular disease propensity score. Dis Colon Rectum 2006;49:629-39.

9. Kwan TL, Lai F, Lam CM, Yuen WC, Wai A, Siu YC, et al. Population-based information on emergency colorectal surgery and evaluation on effect of operative volume on mortality. World J Surg 2008;32:2077-82.

10. Choi KH, Hong YS, Suh SO, Moon HY. Colon perforation. J Korean Soc Coloproctol 1999;15:307-14.

11. Lee KU, Chung JK, Hong SK, Kim ST. Clinical study of colon obstruction. J Korean Surg Soc 1982;24:192-9.

12. Kang DB, Shin CY, Lee JK, Park WC. Multivariate analysis of the risk factors associated with complications and mortality after and emergency operation for obstructive, perforated colorectal cancer. J Korean Soc Coloproctol 2009;25:165-71.

13. Prause G, Ratzenhofer-Comenda B, Pierer G, Smolle-Jüttner F, Glanzer H, Smolle J. Can ASA grade or Goldman's cardiac risk index predict peri-operative mortality? A study of 16,227 patients. Anaesthesia 1997;52:203-6.

14. Horiuchi A, Watanabe Y, Doi T, Sato K, Yukumi S, Yoshida M, et al. Evaluation of prognostic factors and scoring system in colonic perforation. World J Gastroenterol 2007;13:3228-31.

15. Wolters U, Wolf T, Stutzer H, Schroder T. ASA classification and perioperative variables as predictors of postoperative outcome. $\mathrm{Br}$ J Anaesth 1996;77:217-22.

16. Bernard AC, Davenport DL, Chang PK, Vaughan TB, Zwischenberger JB. Intraoperative transfusion of $1 \mathrm{U}$ to $2 \mathrm{U}$ packed red blood cells is associated with increased 30-day mortality, surgicalsite infection, pneumonia, and sepsis in general surgery patients. J Am Coll Surg 2009;208:931-7, 937.e1-2.

17. Post IL, Verheijen PM, Pronk A, Siccama I, Houweling PL. Intraoperative blood pressure changes as a risk factor for anastomotic leakage in colorectal surgery. Int J Colorectal Dis 2012;27:765-72.

18. Pisanu A, Cois A, Uccheddu A. Surgical treatment of perforated diverticular disease: evaluation of factors predicting prognosis in the elderly. Int Surg 2004;89:35-8.

19. Mäkelä JT, Kiviniemi H, Laitinen S. Prognostic factors of perforated sigmoid diverticulitis in the elderly. Dig Surg 2005;22:100-6.

20. Komatsu S, Shimomatsuya T, Nakajima M, Amaya H, Kobuchi T, Shiraishi S, et al. Prognostic factors and scoring system for survival in colonic perforation. Hepatogastroenterology 2005;52:761-4.

21. Leitman IM, Sullivan JD, Brams D, DeCosse JJ. Multivariate analysis of morbidity and mortality from the initial surgical management of obstructing carcinoma of the colon. Surg Gynecol Obstet 1992;174:513-8.

22. Tekkis PP, Kinsman R, Thompson MR, Stamatakis JD; Association of Coloproctology of Great Britain, Ireland. The Association of Coloproctology of Great Britain and Ireland study of large 
bowel obstruction caused by colorectal cancer. Ann Surg 2004; 240:76-81.

23. Khan S, Pawlak SE, Eggenberger JC, Lee CS, Szilagy EJ, Margolin DA. Acute colonic perforation associated with colorectal cancer. Am Surg 2001;67:261-4.

24. Carraro PG, Segala M, Cesana BM, Tiberio G. Obstructing colonic cancer: failure and survival patterns over a ten-year follow-up after one-stage curative surgery. Dis Colon Rectum 2001;44:24350.

25. Tuca A, Guell E, Martinez-Losada E, Codorniu N. Malignant bowel obstruction in advanced cancer patients: epidemiology, management, and factors influencing spontaneous resolution.
Cancer Manag Res 2012;4:159-69.

26. Lee KY, Kim NK, Park JS, Park JK, Lee YC, Min JS. Stent insertion as a bridge to one stage operation in malignant obstruction of left colon (6 cases). J Korean Surg Soc 2001;60:667-70.

27. Hawkins WJ, Moorthy KM, Tighe D, Yoong K, Patel RT. With adequate supervision, the grade of the operating surgeon is not a determinant of outcome for patients undergoing urgent colorectal surgery. Ann R Coll Surg Engl 2007;89:760-5.

28. Zorcolo L, Covotta L, Carlomagno N, Bartolo DC. Toward lowering morbidity, mortality, and stoma formation in emergency colorectal surgery: the role of specialization. Dis Colon Rectum 2003;46:1461-7. 